ARTIKEL PENELITIAN

\title{
HUBUNGAN USIA, PARITAS, DAN KELAS IBU HAMIL DENGAN KOMPLIKASI PERSALINAN DI RSKB SAYANG IBU BALIKPAPAN
}

\author{
Faridah Hariyani ${ }^{1)}$, Ni Nyoman Murti ${ }^{2)}$, Endah Wijayanti ${ }^{3)}$ \\ 1,2,3) Jurusan Kebidanan, Politeknik Kesehatan Kemenkes Kaltim \\ J1. Sorong No. 9 Balikpapan \\ Email : faridahhariyani@gmail.com
}

\begin{abstract}
Maternal mortality (AKI) in Balikpapan the year 2017 has increased from the previous year. Various efforts have been undertaken by the Government to help lower the AKI with of pregnant women class. The scope of of pregnant women class at the Balikpapan is still low and the handling of complications of childbirth has decreased from $99.5 \%$ to $96.87 \%$. The number of labor in RSKB Dear Mother in the year 2017 of 1440 with labor complications by 25\%. The purpose of the research is to find out the relationship between a class of pregnant women with delivery complications on RSKB Dear Mother of Balikpapan. Design research is observational case study controls. The population of the research was the whole maternity in labor period September s.d November RSKB 2018 in Dear Mother of Balikpapan. Sample research 76 of mothers in labor. Data analysis using Chi-Square test, Spearman rho, and Logistic regression. The results showed there was a relationship of pregnant women class with delivery complications with the direction of the negative correlation $(r=-0285 ; p<0.05)$, there are relationship age with delivery complications $(r=0,279 ; p<0.05)$ and there is a relationship of parity with the delivery complications $(r=0,233 ; p<0.05)$. Parity have a greater influence to delivery complications $(O R=0.111 ; p<0.05)$ compared to of pregnant women class $(O R=0,095 ; p<0.05)$. Summary this research there pregnant women class, age and parity relationships with the delivery complications. Parity have a greater influence to delivery complications
\end{abstract}

Keywords: class of pregnant women, age, parity, delivery complications

\begin{abstract}
Abstrak
Angka Kematian Ibu (AKI) di Kota Balikpapan Tahun 2017 mengalami peningkatan dari tahun sebelumnya. Berbagai upaya telah dilakukan oleh pemerintah untuk membantu menurunkan AKI salah satunya dengan program kelas ibu hamil. Cakupan kelas ibu hamil di puskesmas kota Balikpapan masih rendah dan penanganan komplikasi persalinan mengalami penurunan dari 99,5\% menjadi 96,87\%. Tujuan Penelitian adalah untuk mengetahui hubungan antara kelas ibu hamil dengan komplikasi persalinan di RSKB Sayang Ibu Balikpapan. Desain penelitian adalah penelitian observasional studi kasus kontrol. Populasi penelitian adalah seluruh ibu bersalin periode September s.d November 2018 di RSKB Sayang Ibu Balikpapan. Sampel penelitian berjumlah 76 responden. Besar sampel untuk tiap kelompok adalah 38 kelompok kasus dan 38 kelompok kontrol. Analisis data menggunakan uji Spearman rho. Hasil penelitian menunjukkan terdapat hubungan kelas ibu hamil dengan komplikasi persalinan dengan arah korelasi negatif $(r=-0.285 ; p<0,05)$, terdapat hubungan usia dengan komplikasi persalinan $(r=0,279 ; p<0,05)$ dan terdapat hubungan paritas dengan komplikasi persalinan $(\mathrm{r}=0,233 ; \mathrm{p}<0,05)$. Paritas mempunyai pengaruh yang lebih besar terhadap komplikasi persalinan ( $\mathrm{OR}=0,111 ; \mathrm{p}<0.05$ ) dibandingkan dengan kelas ibu hamil $(\mathrm{OR}=0,095 ; \mathrm{p}<0.05)$ Simpulan penelitian terdapat hubungan kelas ibu hamil, usia dan paritas dengan komplikasi persalinan. Paritas mempunyai pengaruh yang lebih besar terhadap komplikasi persalinan.
\end{abstract}

Kata kunci: Kelas Ibu Hamil, Usia, Paritas, Komplikasi Persalinan

\section{PENDAHULUAN}

Program pembangunan kesehatan di

Indonesia dewasa ini masih diprioritaskan pada upaya peningkatan derajat kesehatan Ibu dan anak, terutama pada kelompok yang paling 
rentan kesehatan yaitu ibu hamil, bersalin dan bayi pada masa perinatal. Komplikasi yang terjadi menjelang persalinan, saat dan setelah persalinan terutama karena perdarahan, partus macet atau partus lama dan infeksi akibat trauma pada persalinan (Kemenkes, 2013).

Penyebab terbanyak AKI dan AKB di Indonesia adalah komplikasi obstetrik yaitu sebesar $46.8 \%$. Komplikasi obstetrik salah satunya dipengaruhi oleh status reproduksi ibu atau biasa dikenal dengan istilah 4T (terlalu muda, terlalu tua, terlalu dekat, terlalu sering). Komplikasi persalinan adalah keadaan yang mengancam jiwa ibu ataupun janin karena gangguan sebagai akibat langsung dari kehamilan atau persalinan misalnya perdarahan, infeksi, preeklampsi/eklampsi, partus lama/macet, abortus, ruptura uteri yang membutuhkan manajemen obstetrik (Prawirohardjo, 2014).

Penurunan AKI, merupakan salah satu program prioritas Kementerian Kesehatan. Dalam rangka upaya penurunan angka kematian ibu dan anak, sejak tahun 1997 telah dikembangkan Buku Kesehatan Ibu dan Anak (KIA). Buku KIA diberikan kepada setiap ibu hamil dan dalam buku
KIA tersebut, selain sebagai alat catatan layanan kesehatan yang telah diterima selama hamil sampai janin tersebut lahir hingga usia balita, juga mengandung muatan pengetahuan untuk perawatan ibu hamil dan tanda-tanda komplikasi masa kehamilan dan persalinan hingga masa nifas (Kemenkes,2015)

Selain itu upaya pemerintah untuk membantu menurunkan AKI salah satunya dengan program kelas ibu hamil. Pemerintah Indonesia sejak tahun 2010, telah mengadakan program kelas ibu hamil di tingkat puskesmas. Kelas Ibu Hamil merupakan sarana untuk belajar bersama tentang kesehatan bagi ibu hamil, dalam bentuk tatap muka dalam kelompok yang bertujuan untuk meningkatkan pengetahuan dan keterampilan ibu-ibu mengenai kehamilan, persalinan, nifas, KB pasca persalinan, pencegahan komplikasi, perawatan $\mathrm{BBL}$ dan aktivitas fisik (Kemenkes, 2014)

Kelas ibu hamil difasilitasi oleh bidan/tenaga kesehatan. Pada kelas ini ibu hamil akan belajar bersama, diskusi dan tukar pengalaman tentang kesehatan Ibu dan anak (KIA) secara menyeluruh dan sistematis serta dapat dilaksanakan secara terjadwal dan berkesinambungan. Salah satu indikator output kelas ibu 
hamil adalah persentase ibu yang datang pada K4 semakin meningkat. Semakin tingginya prosentase $\mathrm{K} 4$ diharapkan komplikasi persalinan dapat diminimalisir sehingga AKI dapat menurun (Kemenkes, 2014).

Keikutsertaan ibu hamil dan keluarga pada kelas ibu hamil diharapkan dapat meningkatkan pengetahuan dan perubahan perilaku ibu hamil dan keluarga. Adanya peningkatan pengetahuan dan perubahan perilaku ini diharapkan kesadaran terhadap pentingnya perawatan kesehatan selama kehamilan dan pengenalan tanda komplikasi menjadi meningkat (Depkes, 2009)

Pengetahuan tentang tanda bahaya kehamilan penting untuk diketahui oleh ibu dan keluarganya agar bila terjadi kegawatdaruratan ibu dan keluarga dapat segera mencari pertolongan ke tenaga kesehatan yang terdekat untuk deteksi dini dan segera mendapatkan penanganan yang tepat. Pelayanan yang cepat dan tepat dapat menurunkan AKI dan $\mathrm{AKB}$, namun tidak semua ibu hamil mengetahui adanya tanda bahaya pada kehamilannya. Pengenalan tanda bahaya komplikasi kehamilan ini sebagai upaya kesiapsiagaan ibu dan keluarga dalam menghadapi kejadian komplikasi sehingga dapat mencegah terjadinya kasus kematian ibu (Kemenkes, 2010).

Angka Kematian Ibu (AKI) di Kota Balikpapan tahun 2017 mengalami peningkatan dari tahun sebelumnya dari 9 kasus menjadi 10 kasus. Cakupan penanganan komplikasi obstetrik dan neonatus mengalami penurunan dari 99,5\% menjadi 96,87\%. Target kunjungan kehamilan $\mathrm{K} 4$ di kota Balikapan sebesar 96\% namun cakupan kelas ibu hamil masih dibawah 96\% yang seharusnya targetnya sama dengan kunjungan K4 (Dinkes Balikpapan, 2017). Penelitian ini bertujuan mengetahui hubungan kelas ibu hamil dengan komplikasi persalinan di RSKB Sayang Ibu Balikpapan

\section{METODE PENELITIAN}

Desain penelitian yang digunakan adalah penelitian observasional studi kasus kontrol. Populasi penelitian adalah seluruh ibu bersalin di RSKB sayang Ibu periode September s.d November 2018. Kelompok kasus adalah ibu bersalin dengan komplikasi dan kelompok kontrol ibu bersalin normal dipilih dengan teknik purposive sampling. Besar sampel untuk tiap kelompok adalah 38 kelompok kasus dan 38 kelompok kontrol. 


\section{HASIL DAN PEMBAHASAN}

Tabel 1. Karakteristik Subjek Penelitian berdasarkan Usia, Pendidikan, dan Paritas

\begin{tabular}{lcc}
\hline \multicolumn{1}{c}{ Karakteristik } & Jumlah & $\%$ \\
\hline Usia (tahun) & & \\
$<20$ atau $>35$ & 15 & 20 \\
$20-35$ & 61 & 80 \\
Tingkat pendidikan & & \\
$<$ SMA & 26 & 34 \\
$\geq$ SMA & 50 & 66 \\
Paritas & & \\
$\leq 3$ & 61 & 80 \\
$>3$ & 15 & 20 \\
\end{tabular}

Tabel 2. Hubungan Usia, Paritas dan kelas Ibu Hamil dengan Komplikasi Persalinan

\begin{tabular}{|c|c|c|c|c|}
\hline \multirow[b]{2}{*}{ Variabel } & \multicolumn{2}{|c|}{ Komplikasi } & \multirow[b]{2}{*}{ Nilai p } & \multirow[b]{2}{*}{ Nilai 1} \\
\hline & $\begin{array}{c}\text { Ya } \\
(n=38)\end{array}$ & $\begin{array}{c}\text { Tidak } \\
(\mathrm{n}=38)\end{array}$ & & \\
\hline \multicolumn{5}{|l|}{ Usia (tahun) } \\
\hline $20-35$ & 27 & 30 & & \\
\hline$<20$ atau $>35$ & 11 & 8 & 0,013 & 0,233 \\
\hline \multicolumn{5}{|l|}{ Paritas } \\
\hline$\leq 3$ & 9 & 28 & \multirow{2}{*}{0,003} & \multirow[t]{2}{*}{0,279} \\
\hline$>3$ & 29 & 10 & & \\
\hline \multicolumn{5}{|l|}{ Kelas ibu hamil } \\
\hline Ikut & 3 & 26 & 0,002 & $-0,285$ \\
\hline Tidak Ikut & 35 & 12 & & \\
\hline
\end{tabular}

Ket: diuji dengan Spearman's rho

Terdapat hubungan dengan keeratan cukup kuat antara kelas ibu hamil dengan komplikasi persalinan ( $\mathrm{r}=$ $0,285$ dan nilai $\mathrm{p}<0,05)$ dengan arah korelasi negatif sedangkan pada usia dan paritas terdapat hubungan dengan komplikasi persalinan $(\mathrm{p}<0,05)$ dengan 
keeratan cukup kuat arah korelasi positif.

\section{Pembahasan}

Terdapat hubungan antara kelas ibu hamil dengan komplikasi persalinan dengan arah korelasi negatif. Hal ini dapat diartikan semakin tinggi keikutsertaan kelas ibu hamil semakin rendah komplikasi persalinan. Ibu yang mengikuti kelas ibu hamil memiliki risiko 0.095 kali lebih kecil mengalami komplikasi persalinan dibandingkan dengan ibu hamil yang tidak mengikuti kelas ibu hamil.

Kelas Ibu Hamil adalah kelompok belajar ibu-ibu hamil dengan umur kehamilan antara 4 minggu s/d 36 minggu (menjelang persalinan). Tujuannya adalah meningkatkan pengetahuan, merubah sikap dan perilaku ibu agar memahami tentang pemeriksaan kehamilan, persalinan, nifas, bayi, pencegahan penyakit fisik dan jiwa, gangguan gizi dan komplikasi kehamilan, persalinan, nifas agar ibu dan bayi sehat, perawatan bayi baru lahir agar tumbuh kembang optimal, serta aktivitas fisik ibu hamil (Kemenkes, 2014)

Kelas ibu hamil mempunyai manfaat meningkatkan pengetahuan dan sikap tentang kehamilan dan persalinan. Sesuai hasil penelitian terdapat peningkatan sikap dan pengetahuan kehamilan dan persalinan dari sebelum dan sesudah mengikuti kelas ibu hamil $(\mathrm{p}<0.001)$ (Purworini,2012). Pengetahuan ibu hamil tentang perencanaan persalinan untuk pencegahan komplikasi berhubungan dengan perilaku perencanaan persalinan untuk pencegahan komplikasi $(\mathrm{p}<0,05)$. Kurangnya pengetahuan ibu hamil tentang pentingnya alat transportasi dan pentingnya donor darah (sebagai bagian dari perencanaan persalinan untuk pencegahan komplikasi), berimbas pada tingginya persentase sikap ibu hamil yang kurang baik, dan akhirnya menjadi penyebab tingginya persentase $i b u$ hamil yang memiliki perilaku tidak baik dengan tidak memiliki surat pernyataan kesediaan sarana transportasi dan tidak memiliki surat pernyataan kesediaan menjadi pendonor darah (Maryani S, 2016).

Informasi tentang komplikasi kehamilan dan persalinan dengan kejadian komplikasi persalinan bersifat protektif, dimana ibu yang mendapat informasi cenderung berisiko lebih rendah dibanding ibu yang tidak mendapat informasi. Informasi ini 
diberikan oleh tenaga kesehatan sewaktu ibu mendapatkan pelayanan antenatal. Dalam masa kehamilan, petugas kesehatan harus memberikan pendidikan pada ibu hamil tentang menjaga diri agar tetap sehat dalam masa kehamilan, persalinan dan nifas. Disamping itu juga meningkatkan kesadaran mereka tentang kemungkinan adanya risiko tinggi atau terjadinya komplikasi dalam kehamilan dan persalinan dan cara mengenali komplikasi tersebut (Simarmata \& Bisara, 2010)

Peningkatan pengetahuan tidak selalu menyebabkan perubahan perilaku, tetapi pengetahuan merupakan faktor penting dalam perubahan perilaku. Perilaku dan tindakan dapat dipengaruhi oleh beberapa faktor, salah satunya adalah pengetahuan. Pengetahuan merupakan domain yang sangat penting dalam membentuk perilaku seseorang. Pengetahuan diperlukan sebagai dorongan berfikir dalam menumbuhkan kepercayaan diri maupun dorongan sikap dan perilaku, sehingga dapat dikatakan bahwa pengetahuan merupakan stimulus terhadap tindakan seseorang. Perilaku yang dalam pembentukannya didasari oleh pengetahuan akan bersifat lebih langgeng (Notoatmodjo, 2010).

Frekuensi keikutsertaan dalam kelas ibu hamil berperan penting dalam peningkatan pengetahuan tentang tandatanda bahaya kehamilan dan sikap terhadap respon adanya komplikasi kehamilan. Hasil penelitian menunjukkan bahwa terdapat hubungan yang bermakna antara keikutsertaan ibu hamil pada kelas ibu hamil dengan peningkatan pengetahuan ibu hamil tentang tanda bahaya kehamilan (Sasniatari dkk, 2017). Pada saat ibu hamil mengikuti kelas ibu hamil yang diadakan oleh Puskesmas maka mereka akan mendapatkan informasi yang jelas mengenai seputar kehamilan, persalinan, nifas, perawatan bayi baru lahir dan mengenai tanda bahaya kehamilan (Kemenkes, 2014)

Keikutsertaan ibu hamil dalam kelas ibu hamil merupakan faktor yang berpengaruh terhadap sikap ibu hamil yang baik/positif tentang tanda bahaya kehamilan. Ibu yang mengikuti kelas ibu hamil akan memiliki pengetahuan tentang tanda bahaya kehamilan, ibu akan mendapatkan penjelasan dan sering mendengar tentang tanda bahaya kehamilan pada saat pelaksanaan kelas ibu hamil, hal ini akan meningkatkan 
pengetahuan dan akan mempengaruhi sikap ibu terhadap tanda bahaya kehamilan. Ibu akan lebih waspada dengan kehamilannya dan akan segera mencari pertolongan jika sesuatu hal terjadi pada kehamilannya (Pani, 2011).

Sikap dibentuk oleh tiga struktur yang saling menunjang yaitu komponen kognitif, afektif dan komponen konatif. Komponen kognitif merupakan perwujudan apa yang dipercayai oleh individu pemilik sikap, komponen afektif merupakan perasaan yang menyangkut aspek emosional, dan komponen konatif merupakan aspek kecendrungan berperilaku tertentu sesuai dengan sikap yang dimiliki seseorang. Hal ini juga sesuai dengan The Theory of Palanned Behaviour yang menyatakan bahwa sikap bisa menunjukkan kearah suatu perilaku tertentu dalam mengevaluasi sesuatu baik yang positif maupun negative (Hall, Linzzey, 2011)

Sikap ibu yang positif tentang tanda bahaya kehamilan disebabkan ibu mendapatkan informasi atau pengetahuan yang baik tentang tanda bahaya kehamilan saat pelaksanaan kelas ibu. Tanda bahaya kehamilan ibu diketahui dengan membaca buku KIA dan memperoleh penjelasan dari petugas sehingga ibu menjadi lebih paham tentang tanda bahaya kehamilan. Ibu mengetahui tentang tanda bahaya kehamilan maka ibu hamil tersebut akan berusaha mencari pertolongan ke tenaga kesehatan jika ada tanda bahaya tersebut pada kehamilannya (Sasniatari dkk, 2017).

Pada sikap positif, kecenderungan tindakan adalah mendekati, menyenangi, mengharapkan obyek tertentu, sedangkan dalam sikap negatif terdapat kecenderungan untuk menjauhi, menghindari, membenci, tidak menyukai obyek tertentu (Sumarni et.al, 2013). Salah satu fungsi dari sikap adalah fungsi manfaat dimana fungsi ini menyatakan bahwa individu dengan sikapnya berusaha untuk memaksimalkan hal-hal yang diinginkan dan meminimalkan hal-hal yang tidak diinginkan (Notoatmodjo, 2010).

Metode pemberian informasi yang disampaikan dalam kelas ibu hamil dapat menambah informasi, bila diberikan oleh orang yang tepat dan dikomunikasikan dengan baik dapat menjadi salah satu faktor yang paling mendukung dalam perubahan sikap ibu hamil. Hal ini menjadi penting dalam pemilihan narasumber yang dilibatkan 
dalam program kelas ibu hamil dan memerlukan

kemampuan

berkomunikasi yang baik. Keikutsertaan

kelas ibu hamil dan metode

penyampaian informasi diperlukan

untuk meningkatkan pengetahuan,

terutama hubungan keikutsertaan ibu

dalam kelas ibu hamil (Purwarini, 2012)

Perubahan sikap negatif ibu hamil kearah sikap yang lebih positif terhadap tanda bahaya kehamilan akan berdampak pada pertolongan yang cepat dan tepat jika terjadi sesuatu hal dengan kehamilannya sehingga akan mencegah komplikasi kehamilan yang akan menyebabkan kesakitan dan kematian ibu dan bayi.

Terdapat hubungan yang bermakna antara pengetahuan ibu hamil yang baik tentang tanda bahaya kehamilan dengan sikap ibu menjadi positif dalam menghadapi tanda bahaya kehamilan dan persalinan. Tujuan pendidikan kesehatan adalah mengubah perilaku orang atau informasi yang diberikan kepada ibu hamil memberikan banyak manfaat dimana tanda bahaya kehamilan dapat diketahuinya, sehingga ibu hamil dapat mewaspadai kalau mengalami salah satu dari tanda bahaya kehamilan dapat segera mencari pertolongan ke bidan ataupun tenaga kesehatan lainnya yang pada akhirnya dapat mengurangi resiko komplikasi dari tanda bahaya kehamilan tersebut (Sefita\&Farid, 2011).

Ibu yang berumur $<20$ tahun dan >35 tahun merupakan faktor risiko untuk terjadinya komplikasi persalinan. Terdapat hubungan antara usia ibu dengan komplikasi persalinan. Ibu dengan usia 20-35 memiliki risiko 1/4 kali lebih kecil untuk mengalami komplikasi persalinan daripada ibu dengan usia $<20$ tahun atau $\geq 35$ tahun (Maryani S, 2016).

Wanita yang hamil pada usia risiko tinggi dapat menimbulkan penyulit baik pada ibu maupun bayinya, hal ini dikarenakan ibu yang terlalu muda kurang dari 20 tahun masih belum memiliki alat reproduksi yang matang dan kondisi rahim belum sempurna untuk hamil dan melahirkan, sedangkan bagi ibu yang terlalu tua lebih dari 35 tahun memungkinkan untuk terjadi komplikasi kebidanan karena kesehatan reproduksi sudah menurun dan tidak mampu untuk mengejan (Mochtar, 2013).

Studi ini melaporkan bahwa ibu yang berumur kurang dari 20 tahun atau lebih dari 35 tahun berisiko untuk mengalami komplikasi persalinan 
sebesar 1.3 kali dibandingkan dengan ibu yang berumur 21-34 tahun. Wanita yang hamil di bawah usia 20 tahun lebih berisiko terjadi abortus, anemia, malnutrisi, hipertensi, preeklampsia dan eklampsia

Usia berkaitan dengan ketidaksiapan ibu dalam reproduksi, wanita usia dibawah 20 tahun masih berada dalam tahap pertumbuhan dan perkembangan sehingga kondisi hamil akan membuat dirinya harus berbagi dengan janin yang sedang dikandung untuk memenuhi kebutuhan gizinya. Sebaliknya ibu yang berumur lebih dari 35 tahun mulai menunjukkan pengaruh poses penuaannya, seperti sering muncul penyakit seperti hipertensi dan diabetes melitus yang dapat meghambat masuknya makanan janin melalui plasenta (Prawirohardjo, 2013). Pada usia muda organ-organ reproduksi dan fungsi fisiologisnya belum optimal dan secara psikologis belum tercapainya emosi yang cukup sehingga akan berpengaruh terhadap penerimaan kehamilannya yang akhirnya akan berdampak pada proses kehamilan dan persalinan.

Terdapat hubungan antara paritas dan komplikasi persalinan dengan arah korelasi positif. Hal ini dapat diartikan semain tinggi paritas semakin tinggi komplikasi persalinan. Ibu dengan paritas tinggi memiliki risiko 0,111 lebih besar mengalami komplikasi persalinan dibandingkan dengan ibu paritas rendah.

Primipara dan grandemultipara $\geq 4$ anak berisiko 1,08 kali mengalami komplikasi persalinan dibandingkan multipara 2-3 anak. Persalinan yang kedua dan yang ketiga merupakan persalinan yang paling aman, risiko akan semakin meningkat pada kehamilan selanjutnya. Persalinan pertama yang berisiko hanya dapat diatasi dengan asuhan antenatal yang lebih baik. Kejadian preeklampsi dan eklampsia lebih sering terjadi selama kehamilan anak yang pertama dan jarang pada kehamilan berikutnya. (Manuaba, 2013)

Ibu dengan paritas tinggi akan mempunyai risiko yang lebih besar terhadap kejadian komplikasi persalinan terutama perdarahan postpartum. Pada ibu yang sering melahirkan, otot uterusnya sering diregangkan sehingga mengakibatkan menipisnya dinding uterus yang akhirnya menyebabkan kontraksi uterus menjadi lemah. Ruptur uterus merupakan komplikasi persalinan yang sering terjadi pada ibu yang 
sebelumnya telah melahirkan beberapa orang anak (Aprilia, 2012).

Primipara memiliki kemungkinan untuk tidak mengalami kejadian komplikasi berupa placenta previa sebesar 11,69 kali lebih besar dari pada ibu yang paritas multipara/lebih (Mahalingam, 2014) Paritas 2-3 merupakan paritas paling aman ditinjau dari sudut kematian maternal. Paritas 1 dan paritas tinggi (lebih dari 3) mempunyai angka kematian maternal lebih tinggi. Lebih tinggi paritas, lebih tinggi kematian maternal. Risiko pada paritas satu dapat ditangani dengan asuhan obstetrik lebih baik, sedangkan risiko pada paritas tinggi dapat dikurangi atau dicegah dengan keluarga berencana. Sebagian kehamilan pada paritas tinggi adalah tidak direncanakan (Manuaba, 2013)

Berdasarkan rumusan dari Poedji Rochjati (2003) dan Harry Oxorn (2010) dapat diketahui bahwa paritas dengan risiko tinggi dapat menyebabkan komplikasi selama masa kehamilan, persalinan, maupun masa nifas. Pada primipara sering terjadi komplikasi namun tidak seluruhnya ibu primipara berisiko mengalami komplikasi, tergantung kesiapan fisik dan psikologi ibu hamil. Pada grandemultipara faktor yang berpengaruh dan mengancam adalah berkaitan dengan fungsi organ reproduksi yang sudah menurun sehingga dapat mengakibatkan komplikasi dalam kehamilan maupun persalinan. Penanganan pada paritas satu dapat yaitu dengan asuhan kehamilan dan persalinan yang diharapkan fisiologis dan memenuhi standart. Sedangkan pada paritas tinggi dapat dikurangi atau dicegah dengan keluarga berencana.

Kejadian plasenta previa meningkat pada multipara. Dalam penelitian didapatkan hasil bahwa wanita multipara memiliki risiko 11,69 kali lebih besar untuk mengalami plasenta previa daripada wanita primipara (Sengoma, 2017). Paritas yang tinggi kejadian plasenta previa makin besar karena endometrium belum sempat tumbuh. Mekanisme terjadinya plasenta previa pada multipara adalah corpus uteri merupakan bagian atas rahim yang mempunyai dinding otot paling tebal, sehingga dalam keadaan normal, plasenta berimplantasi pada daerah corpus uteri, pada kehamilan berikutnya keadaan endometrium pada daerah corpus uteri mengalami kemunduran fungsi dan kekurangan vaskularisasi. Hal ini dikarenakan terjadinya 
degenerasi dan nekrosis pada bekas luka implantasi plasenta sewaktu kehamilan sebelumnya di endometrium pada corpus uteri. Keadaan endometrium yang kurang baik menyebabkan plasenta harus tumbuh menjadi luas untuk mencukupi kebutuhan janin (Muchtar, 2013).

Kejadian plasenta previa meningkat dengan meningkatnya paritas ibu. Konsep "Migrasi Plasenta" yang menjadi predisposisi plasenta previa pada multipara. Banyaknya kejadian placenta previa pada ibu hamil multipara dimungkinkan karena jaringan parut uterus akibat kehamilan berulang. Jaringan parut ini menyebabkan tidak adekuatnya persediaan darah ke plasenta sehingga plasenta menjadi lebih tipis dan mencakup daerah uterus yang lebih luas. Oleh karena itu, diperlukan konseling dalam memberikan asuhan yang tepat khususnya pada ibu hamil untuk mengatur jumlah dan jarak kehamilan anak atau dengan mengikuti program keluarga berencana (Manuaba, 2013)

\section{SIMPULAN}

Terdapat hubungan usia, paritas dan kelas ibu hamil dengan komplikasi persalinan di RSKB Sayang Ibu Kota Balikpapan sehingga diharapkan kehamilan dapat direncanakan dengan tepat. Pelaksanaan program kelas ibu diharapkan dilakukan secara rutin sebagai upaya preventif dan deteksi dini adanya komplikasi kehamilan dan persalinan.

\section{UCAPAN TERIMAKASIH}

Ucapan terimakasih kepada Direktur Poltekkes Kemenkes Kaltim, Ka.Unit Litbang, Ketua Jurusan Kebidanan dan Direktur RSKB Sayang Ibu Balikpapan yang telah memberikan kerjasama yang baik dalam penelitian ini. Penelitian ini dibiayai oleh anggaran DIPA Poltekkes Kaltim tahun 2018 untuk Skema Penelitian Pemula dengan Nomor SK: PP.03.01/1.1/4734/2018 Tanggal 6 Juli 2018

\section{DAFTAR PUSTAKA}

Aprilia D. (2012). Karakteristik ibu bersalin yang mengalami perdarahan postpartum primer di RSUD Panembahan Senopati Bantul Tahun 2012. Jurnal Stikes Aisyiyah Yogyakarta, 46-48.

Dahlan S. (2010). Besar sampel dan cara pengambilan sampel dalam penelitian kedokteran dan 
kesehatan. Jakarta. Salemba Medika, 23-24.

Depkes.(2009). Pedoman Umum

Manajemen Penerapan Buku KIA

(2009). from: $\quad$ http://

perpustakaan. depkes. go. id:

8180/ bitstream/123456789/

802/4/BK2009-G124.pdf

Dinkes Kota Balikpapan. (2017). Profil

Kesehatan Kota Balikpapan.

Hall S C; Lindzey G. (2012). Psikologi kepribadian 3. Teori-teori Sifat dan Behavoiristik. . A S, editor. Yogyakarta. from: http:// library. fip. uny. ac. $\mathrm{Id} /$

opac/index.php?p=show_detail\&i $\underline{\mathrm{d}=424}$

Ismael S, Sastroasmoro S. (2011). Dasar-dasar metodologi penelitian klinis. Edisi ke-4. Jakarta: Sagung Seto. 65-66.

Kemenkes RI. (2015). Buku Kesehatan Ibu dan Anak. Dirjen Bina Gizi dan Kesehatan Ibu dan anak. Jakarta. 14-15

Kemenkes RI. (2013). Buku Saku Pelayanan Kesehatan Ibu di fasilitas kesehatan dasar dan rujukan Edisi I. Dirjen Bina Gizi dan Kesehatan Ibu dan anak. Jakarta. 16-17
Kemenkes RI. (2014). Pedoman Pelaksanaan Kelas Ibu Hamil. Dirjen Bina Gizi dan Kesehatan Ibu dan anak. Jakarta. 8-9

Kemenkes RI. (2010). Rencana Operasional Promosi Kesehatan Ibu dan Anak. Dirjen Bina Gizi dan Kesehatan Ibu dan anak. Jakarta. 6-8

Mahalingam, G., \& Venkateasan, M. (2014). Mother and knowledge of warning signs of pregnancy, labour and puerperium. International Journal of Medical Science and Public Health, 3(6), 720.

Manuaba I. (2013). Ilmu Kebidanan, penyakit kandungan dan $\mathrm{KB}$. Edisi 2. Jakarta. EGC. 55-56

Maryani, S., Respati, S. H., \& Astirin, O. P. (2016). Association Between Pregnant Woman Class and Pregnancy Complication in Tegal District, Central Java. Journal of Maternal and Child Health, 1(4), 214-219

Mochtar R. (2013). Sinopsis Obstetri. Edisi Kedua Jilid 1. Jakarta. EGC.22-23.

Notoatmodjo S. (2010). Promosi kesehatan dan ilmu perilaku. 
Edivi revisi. Jakarta. Rineka Cipta, 22-23.

Nurgi, S., Tachbele, E., Dibekulu, W., \& Wondim, M. A. (2017). Knowledge, Attitude and Practice of Obstetric Danger Signs during Pregnancy in Debre Berhan, Ethiopia. Health Science Journal, 11(6), 1-7.

Pani W, Masni BB. (2011). The effect of prenatal plus class on knowledge and attitude of pregnant women in the working area of Mamboro Health centre north Palu district cental Sulawesi Province. Makasar

Prawirohardjo S. (2014). Ilmu Kebidanan. Edisi keempat. Jakarta. PT Bina Pustaka Sarwono Prawirohardjo. 45-46.

Purwarini D. (2012). Pengaruh Kelas Ibu Hamil terhadap Pengetahuan dan Sikap Ibu dalam Kehamilan dan Persalinan di Wilayah Puskesmas Gurah Kabupaten Kediri. UNS Solo. 33-35.

RSKB Sayang Ibu. (2017). Profil RSKB Sayang Ibu. Balikpapan.

Sasnitiari, N. N., Supliyani, E., Rosaria, Y. W., Puspitasari, D. A (2017). Hubungan Keikutsertaan Ibu dalam Kelas Ibu Hamil dengan
Pengetahuan dan Sikap Terhadap Tanda Bahaya dalam Kehamilan di Kota Bogor. Jurnal Kesehatan Reproduksi, 8(2), 175-185.

Satari MH, Wirakusumah FF. (2011) Konsistensi penelitian dalam bidang kesehatan. Bandung: PT Refika Aditama. 24-26.

Sefitia M., Farid A. (2012). Pengetahuan Ibu Hamil Tentang Tanda Bahaya Kehamilan Dan Tanda Persalinan Sebelum Dan Sesudah Mendapatkan Promosi Kesehatan Di Desa Mekarwangi Kecamatan Ibun Kabupaten Bandung Tahun 2011. Program Studi Diploma III Kebidanan Fak Kedokt Univ Padjadjaran. from: http://www.medicaobgin.ac.id/ journal Detail. Php/id/MjY

Sengoma, J. P. S., Krantz, G., Nzayirambaho, M., Munyanshongore, C., Edvardsson, K., \& Mogren, I. (2017). Prevalence of pregnancyrelated complications and course of labour of surviving women who gave birth in selected health facilities in Rwanda: A health facility-based, cross-sectional study. BMJ Open, 7(7). 
Simarmata, OS; Armagustini, Y; Bisara, D; (2012). Determinan Kejadian Komplikasi Persalinan di Indonesia (Analisis Data Sekunder Survei Demografi dan Kesehatan Indonesia Tahun 2007. Jurnal Ekologi Kesehatan, 6-7. 